\title{
Improved Modified DTC-SVM Methods for Increasing the Overload-capability of Permanent Magnet Synchronous Motor Servo- and Robot Drives - Part 2
}

\author{
Tibor Vajsz*, László Számel1 \\ ${ }^{1}$ Department of Electric Power Engineering, Faculty of Electrical Engineering and Informatics, \\ Budapest University of Technology and Economics, H-1521 Budapest, P.O.B. 91, Hungary \\ * Corresponding author, e-mail: vajsz.tibor@vet.bme.hu
}

Received: 29 November 2017, Accepted: 14 May 2018, Published online: 25 May 2018

\begin{abstract}
Direct torque control with space vector modulation (DTC-SVM) is one of the most popular methods in the case of permanent magnet synchronous motor drives due to its excellent torque-control capabilities. This method facilitates a very high torque-control dynamic performance which is an especially important requirement in the field of servo- and robotic applications, thus making DTC-SVM a natural choice in these cases. In this article simplified forms of the Improved Modified DTC-SVM (IMDTC-SVM) method that has been introduced in Part 1 are presented and it is proven that these methods have a very high overload-capability as well, they are stable during overload-conditions, while the torque-control dynamics and the torque-ripple generated are practically identical with those of the classical DTC-SVM, the MDTC-SVM and the standard IMDTC-SVM. Although the simplified forms have a somewhat lower overloadcapability than that of the standard IMDTC-SVM, they have a significantly simpler structure, they require much less computation and the tuning of the complete control system is in one case much simpler.
\end{abstract}

Keywords

permanent magnet synchronous motor, direct torque control, space vector modulation, servo drive, robot drive, frequency converter, electric drive

\section{Introduction}

Permanent magnet synchronous motors (PMSMs) are nowadays extensively used which can be contributed mainly to their high power-density and high efficiency [1]. They are widely used in electric vehicles [2], in high-speed drives $[3,4]$ and in servo drives [5], along with stepping motors [6].

Many methods have been developed for controlling the electromagnetic torque of PMSMs. One of these methods is called direct torque control (DTC) which is famous for its excellent dynamic torque-control capabilities in the case of PMSMs, induction motors, etc. [7-13]. The method has been generalized for network-connected voltage source converters providing an excellent dynamic control of the power flow between the network and the DC-bus [14-18]. This is called Direct Power Control (DPC) [14-18]. However, DTC produces excessive amount of torque-ripple during operation along with varying switching frequency $[7,11]$, which are undesirable in the case of servoand robot drives. DTC-SVM grants fixed switching frequency and the torque-ripple is significantly reduced compared to DTC, while the dynamics of the torque-control is essentially identical to that of the traditional DTC [19-21]. Therefore, DTC-SVM is considered as one of the research areas that is currently in the centre of interest within the DTC-topic [22-29].

However, the overload-capability of DTC-SVM methods is an issue that has not been thoroughly investigated yet. This article focuses on this issue and proposes two simplified forms of the Improved Modified DTC-SVM (IMDTC-SVM) method that has been introduced in Part 1. The two simplified forms have a significantly higher overload-capability than that of either the MDTC-SVM introduced in [30] or the classical DTC-SVM. Although the simplified forms have a slightly lower overload-capability than that of the standard IMDTC-SVM, they are remarkably simpler in structure, they require significantly less computation and the tuning of the complete control system is in one of the two cases much simpler. This article is intended to continue the thread of [30] and Part 1. 


\section{Terminology, notations}

The basic equations of permanent magnet synchronous motor drives are well-detailed in [11, 30]. The terminology, the abbreviations and the notations will be the same as in [30] and in Part 1 for detailed information see [30] and Part 1. Also, like [30] and Part 1, this article assumes a surface-mounted permanent magnet synchronous motor.

\section{Simplified forms of Improved Modified DTC-SVM}

The general block diagram of the simplified forms of IMDTC-SVM can be seen on Fig. 1. A simplified form of the improved estimator described in Part 1 (IEST-SF) is used to estimate the variables that are required by a simplified form of the improved predictive controller described in Part 1 (IPC-SF) in order to perform the control algorithm. The IPC-SF computes the voltage vector reference that is synthesized by the two-level voltage source inverter (VSI) using space vector modulation $(S V M)$. (A detailed description of space vector modulation can be read in [11, 30-32].)

$\psi_{c 1}$ and $\psi_{c 2}$ are the real- and the imaginary axis components of the stator flux vector, respectively. In the case of IMDTC-SVM simplified form XY (SFXY) $\psi_{c 1}=\psi_{x}$ and $\psi_{c 2}=\psi_{y}$, while in the case of IMDTC-SVM simplified form DQ (SFDQ) $\psi_{c 1}=\psi_{d}$ and $\psi_{c 2}=\psi_{q}$. Also, it must be noted that the IPC-SF receives the angular position of the rotor $(\theta)$ as a parameter instead of the load-angle. The block diagram of the improved estimator in the case of SFXY (IEST-SFXY) can be seen on Fig. 2, while the improved estimator in the case of SFDQ (IEST-SFDQ) can be seen on Fig. 3 .

The general block diagram of the simplified form of the improved predictive controller (IPC-SF) can be seen on Fig. 4. The IPC-SF consists of four blocks: the same stator flux amplitude reference controller that has been described in Part $1\left(\psi_{\text {ref }} c t r l\right)$, the simplified reference controller (Ref. ctrl SF), the flux vector controller (Flux vector ctrl) and a simplified form of the adaptive voltage vector calculator described in Part 1 ( $A V V C S F)$.

The simplified reference controller is shown on Fig. 5. It is the same as the reference controller described in Part 1, except that it does not compute $\psi_{\text {ref }}$ and $\delta_{\text {ref }}$ and does not apply any limitation. The simplified reference controller uses Eq. (4) from Part 1 in order to compute $\psi_{q \text {,ref }}$ and based on $\psi_{\text {ref, } m}$ and $\psi_{q, r e f} \psi_{d, r e f}$ is calculated using Eq. (7) from Part 1 . The calculated $\psi_{d \text {,ref }}$ and $\psi_{q, \text { ref }}$ are input to the flux vector controller. Fig. 6 shows the flux vector controller of SFXY while Fig. 7 shows that of the SFDQ.

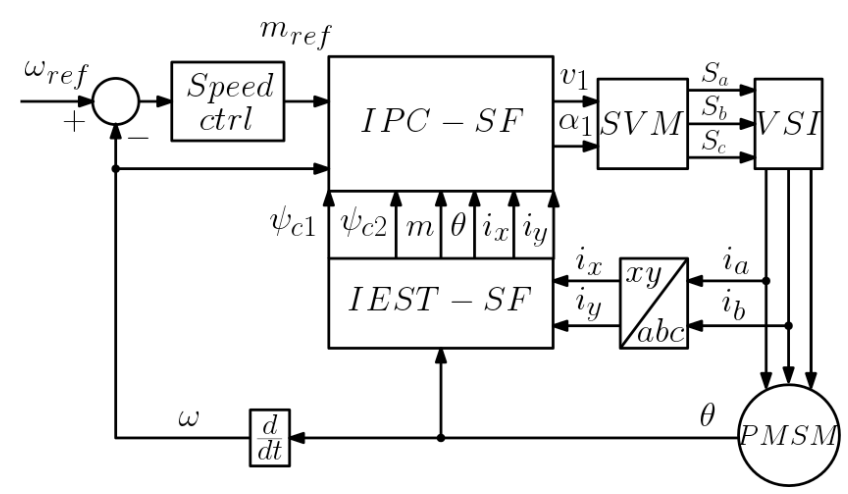

Fig. 1 IMDTC-SVM SF

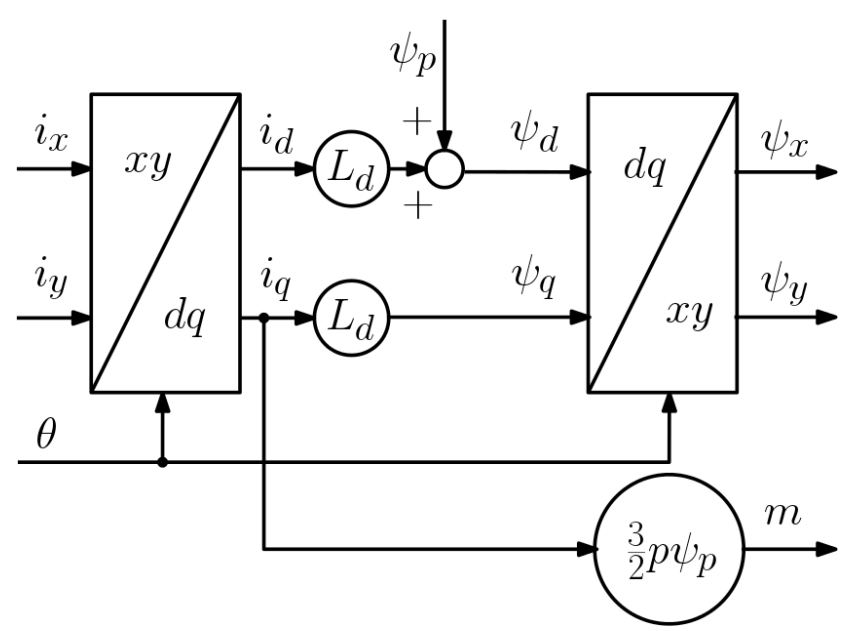

Fig. 2 IEST-SFXY

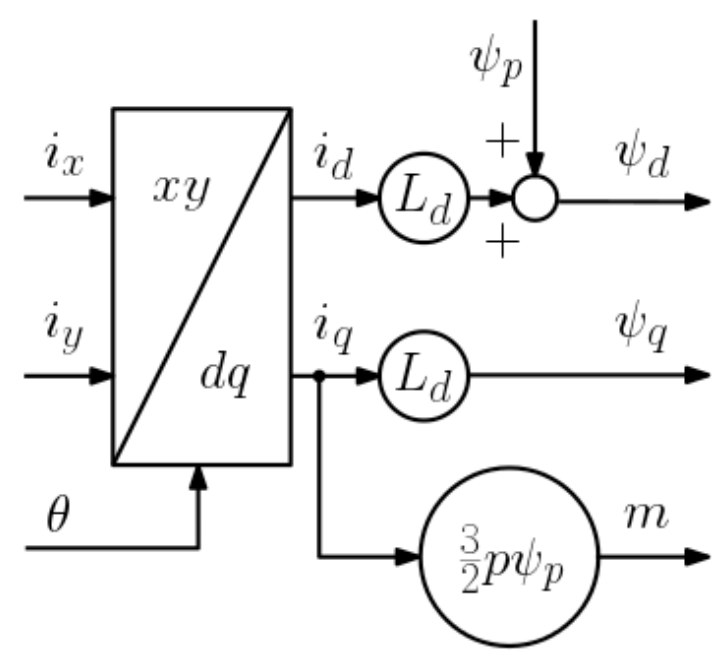

Fig. 3 IEST-SFDQ

In the case of the flux vector controller of SFXY the flux vector reference is transformed from the rotor reference frame to the stationary reference frame and then each component is controlled by a P-type controller. The output of both controller $\left(v_{x, r}\right.$ and $\left.v_{y, r}\right)$ is fed into the voltage vector calculator. Due to the fact that $\psi_{x, \text { ref }}$ and $\psi_{y, \text { ref }}$ 


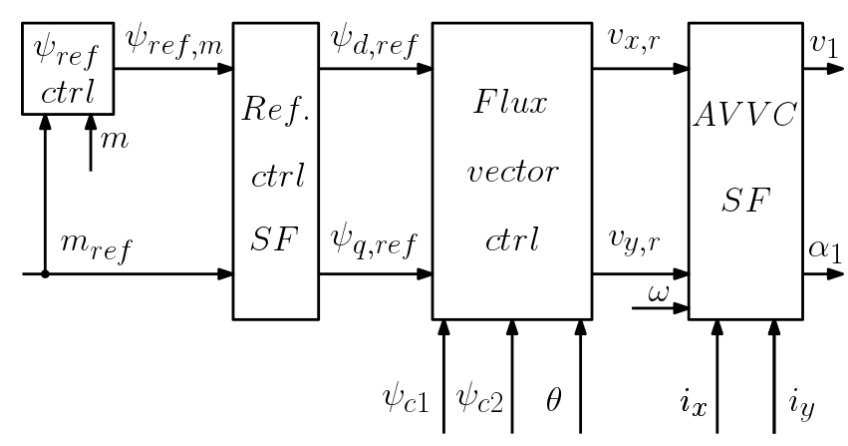

Fig. 4 IPC-SF

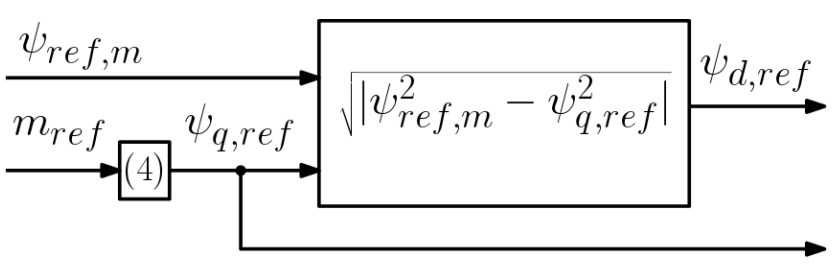

Fig. 5 Reference controller SF

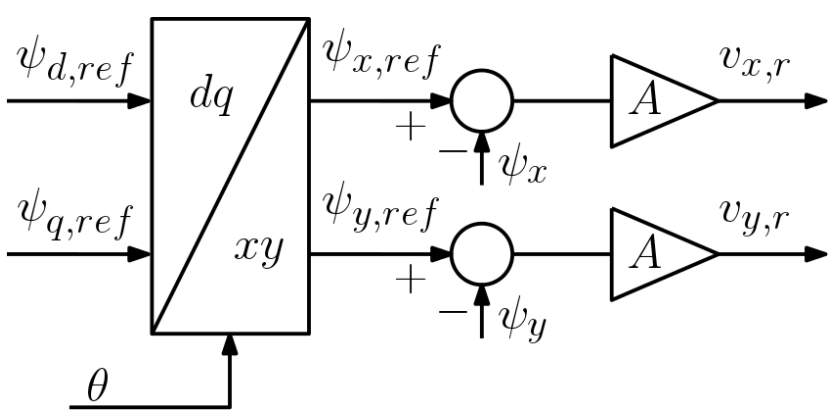

Fig. 6 Flux vector controller of SFXY

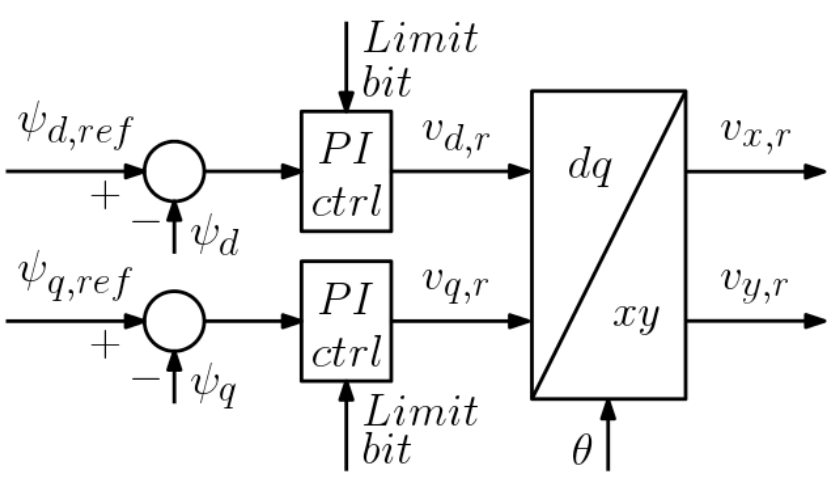

Fig. 7 Flux vector controller of SFDQ

are sinusoidal in steady-state the utilization of I-terms in the controllers is disadvantageous. The gain of the two P-type controllers must be set to equivalent values otherwise asymmetry is caused in the voltage vector reference. This means that the tuning of the control system of IMDTC-SVM SFXY is significantly easier than that of the standard IMDTC-SVM because - except for the $\psi_{\text {ref }}$-controller - there is only one parameter to set whereas in the case of standard IMDTC-SVM there are four parameters to set (due to the two PI-type controllers). Also, there is no limitation applied in the flux vector controller of SFXY, thus the amplitude of the voltage vector reference is limited in the voltage vector calculator only (this type of limitation is applied in the other forms of DTC-SVM as well: in classical DTC-SVM, in MDTC-SVM and in all forms of IMDTC-SVM).

The flux vector controller of SFDQ is more complex than that of the SFXY. It uses PI-type controllers which means that the tuning of the control system is more difficult than in the case of SFXY. The two PI-type controllers synthesize the two components of the voltage vector reference $\left(v_{d, r}, v_{q, r}\right)$ that - after a transformation into the stationary reference frame - are fed to the voltage vector calculator $\left(v_{x, r}, v_{y, r}\right)$. Also, there is a limit bit which is used for halting the integration in the PI-type controllers if the amplitude of the voltage vector reference has reached the limit set in the voltage vector calculator (this limit is the DC-bus voltage divided by $\sqrt{3}$ due to the fact that SVM is used to synthesize the voltage vector reference).

The $A V V C S F$ is the same as $A V V C$ in Part 1, except that instead of Eqs. (10), (11), (14) and (15) in Part 1 it uses simpler equations in order to compute $v_{x, \text { ref }}$ and $v_{y, r e f}$. If the absolute value of the speed is below the prescribed limit the following equations are used instead of Eq. (10) and Eq. (11) in Part 1:

$$
\begin{aligned}
& v_{x, r e f}=v_{x, r}+R i_{x} \\
& v_{y, r e f}=v_{y, r}+R i_{y} .
\end{aligned}
$$

If the absolute value of the speed is greater than the prescribed limit the following equations are used instead of Eq. (14) and Eq. (15) in Part 1:

$$
\begin{aligned}
& v_{x, r e f}=v_{x, r} \\
& v_{y, r e f}=v_{y, r} .
\end{aligned}
$$

\section{Simulation results for torque-ripple and torque- control dynamics}

Simulation was carried out for a synchronous servo motor in Matlab-Simulink environment, using the same parameters as in [30] and Part 1. The parameters can be found in Table 1 of [30]. Investigations were carried out for the normal operation region only. The simulation used the same optimized switching strategy for space vector modulation as in [30] and Part 1. Current-limitation was also 
implemented during the investigations in the same way as in [30] and Part 1. Current-limit was set to $600 \%$ of the nominal current during the simulations like in [30] and Part 1. $m_{\text {limit }}$ was set to $6.2 \mathrm{Nm}$ in the case of SFXY, while in the case of SFDQ it was set to $6.4 \mathrm{Nm}$.

The simulated process is the same as in section 4 of Part 1, except that the torque-reference is limited to 7.5 $\mathrm{Nm}$. Fig. 8 shows the torque-reference and the electromagnetic torque vs. time for a $3000 \mathrm{rpm}$ speed-reference in the case of SFXY, while Fig. 9 shows the same for SFDQ. The time is given in milliseconds on the horizontal axis of both figures. Table 1 and Table 2 show the results for the RMS of the torque-ripple in percentage of the mean-torque for SFXY and SFDQ, respectively.

According to Table 1 and Table 2 of this article and Table 1 of Part 1 there is no significant difference between IMDTC-SVM SFXY, IMDTC-SVM SFDQ and standard IMDTC-SVM in regard of the RMS of the torque-ripple. Also, based on Fig. 8 and Fig. 9 of this article and Fig. 10 of Part 1 it can be concluded that the torque-control dynamic performance of the three methods is practically identical. Also, it can be concluded from the former statements and section 4 of Part 1 that there is no significant difference between IMDTC-SVM SFXY, IMDTCSVM SFDQ, MDTC-SVM and classical DTC-SVM from the point of view of the torque-ripple generated and the torque-control dynamic performance.

\section{Overload-capability of the simplified forms}

Investigations were carried out with the same parameters as in Section 4 (same current limit, etc.). The simulated process is the following: there is a speed-reference step of $3000 \mathrm{rpm}$ value at $0 \mathrm{~ms}$ and then a load-torque step of $6.5 \mathrm{Nm}$ value at $50 \mathrm{~ms}$. The torque-reference is limited to $7.5 \mathrm{Nm}$ in both cases. The time is given in milliseconds on the horizontal axis of all figures. Figs. 10-14 show the results for SFXY, while Figs. 15-19 show the results for SFDQ.

As it can be seen on Fig. 10 and Fig. 15 both SFXY and SFDQ are able to compensate for the load-torque step, which means that both methods have a significantly higher overload-capability than that of the MDTC-SVM, which is able to compensate for a maximum of $5.5 \mathrm{Nm}$ loadtorque step only [30].

According to Fig. 11 and Fig. 16 the electromagnetic torque equals to the load-torque in steady-state in both cases. However, after the load-torque step has been compensated, the electromagnetic torque is practically equal to the torque-reference in the case of SFDQ, while in
Table 1 RMS torque-ripple in percentage of the mean-torque for SFXY

\begin{tabular}{ccccc}
\hline $\begin{array}{c}\text { Speed } \\
(\mathrm{rpm})\end{array}$ & 0 & 1000 & 2000 & 3000 \\
\hline 0.5 & 0.1836 & 0.2698 & 0.5988 & 1.1986 \\
1 & 0.0843 & 0.1329 & 0.3189 & 0.6646 \\
2 & 0.0703 & 0.0768 & 0.2177 & 0.4004 \\
\hline
\end{tabular}

Table 2 RMS torque-ripple in percentage of the mean-torque for SFDQ

\begin{tabular}{|c|c|c|c|c|}
\hline $\begin{array}{c}\text { Torque } \\
(\mathrm{Nm})\end{array}$ & 0 & 1000 & 2000 & 3000 \\
\hline 0.5 & 0.2444 & 0.5729 & 0.5864 & 1.2131 \\
\hline 1 & 0.0821 & 0.2899 & 0.4147 & 0.6368 \\
\hline 2 & 0.1068 & 0.1392 & 0.2438 & 0.3911 \\
\hline
\end{tabular}

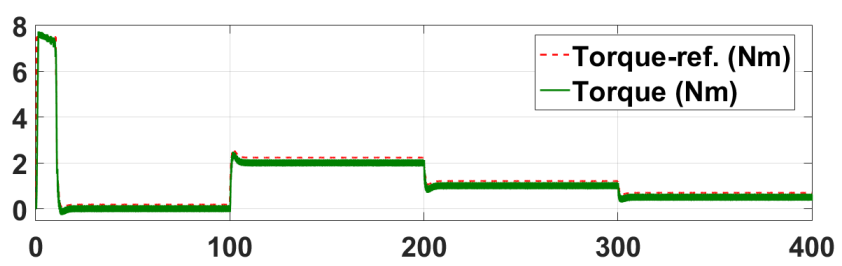

Fig. $8 m_{r e f}$ and $m$ vs. time for a $3000 \mathrm{rpm}$ speed-ref. for SFXY

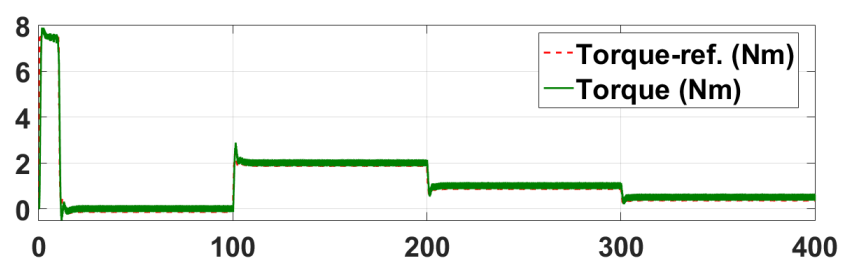

Fig. $9 m_{r e f}$ and $m$ vs. time for a $3000 \mathrm{rpm}$ speed-ref. for SFDQ

the case of SFXY the torque-reference is greater than the electromagnetic torque. The latter can explained by the fact that the $\psi_{\text {ref }}$-controller is already active $\left(m_{\text {limit }}\right.$ is $6.2 \mathrm{Nm}$ and the load-torque is $6.5 \mathrm{Nm}$ ) and the flux vector controller uses P-type controllers. Due to the fact that both the $\psi_{\text {ref }}$-controller and the flux vector controller are using P-type controllers they require nonzero error-signal in order to produce nonzero output. Therefore, the torque-reference is raised by the speed-controller (which is a PI-type controller), in order to make the compensation possible. This applies in the case of normal operation (no overloading) as well because the flux vector controller uses P-type controllers (see Fig 8). However, in the case of SFDQ the $\psi_{\text {ref }}$-controller is barely active $\left(m_{\text {limit }}\right.$ is $6.4 \mathrm{Nm}$ and the load-torque is $6.5 \mathrm{Nm}$ ) which means that the difference between the electromagnetic torque and the torque reference is so small that it is covered by the ripples of the 


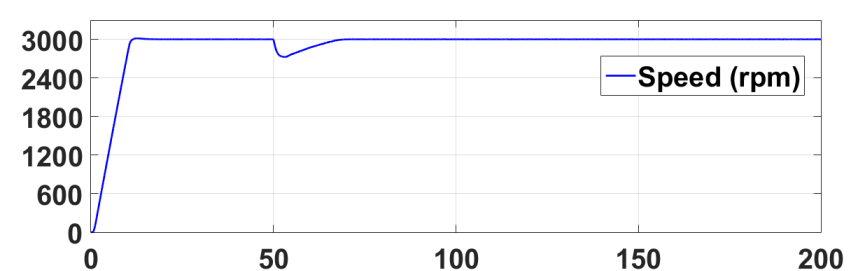

Fig. 10 Speed vs. time during overloading for SFXY

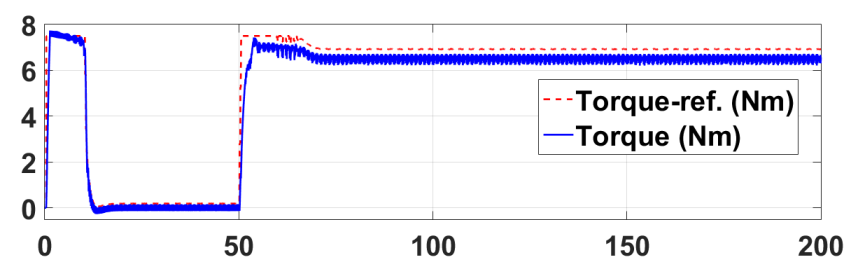

Fig. $11 m_{r e f}$ and $m$ vs. time during overloading for SFXY

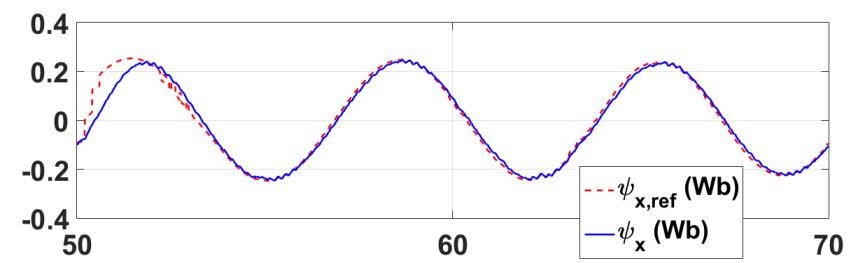

Fig. $12 \psi_{x, r e f}$ and $\psi_{x}$ vs. time during overloading for SFXY

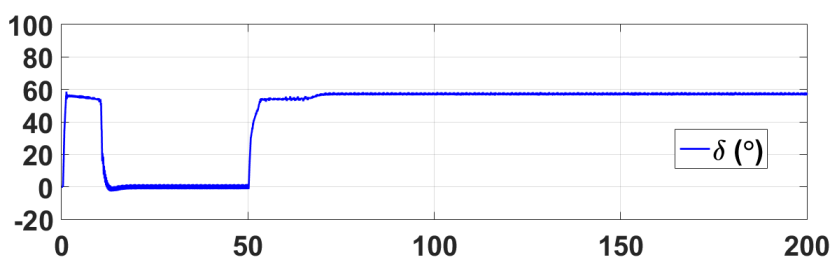

Fig. $13 \delta$ (in degrees) vs. time during overloading for SFXY

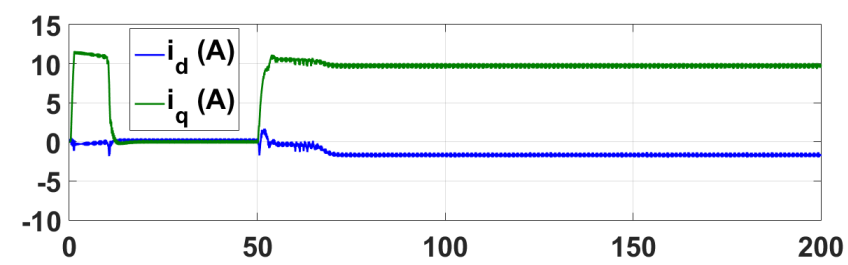

Fig. $14 i_{d}$ and $i_{q}$ vs. time during overloading for SFXY

electromagnetic torque and thus it is invisible on Fig. 16. However, the activation point of the $\psi_{\text {ref }}$-controller can be noticed on both Fig. 11 and Fig. 16 which is when the slope of the rising electromagnetic torque changes.

Fig. 12 and Fig. 17 show the flux controlling capabilities of the two methods. In the case of Fig. 12 only the loadtorque transient is shown for better visibility. It can be clearly seen on Fig. 12 that the tracking is not error-free. This is because P-type controllers are being used in the flux vector controller of SFXY. The activation of the $\psi_{\text {ref }}$-controller is also visible on Fig. 12, which is at the beginning

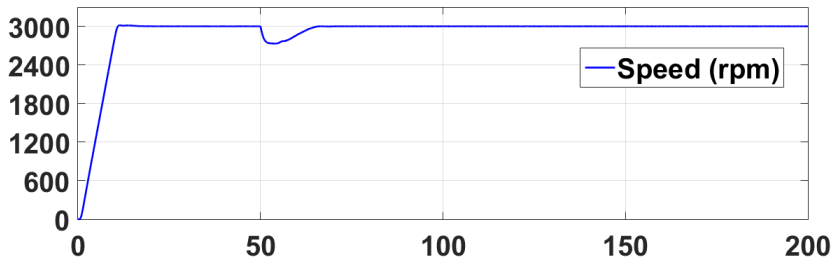

Fig. 15 Speed vs. time during overloading for SFDQ

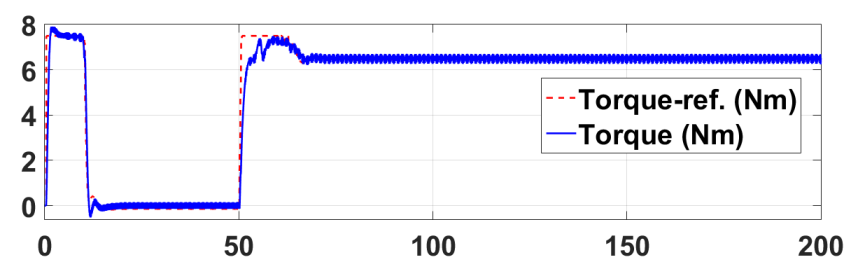

Fig. $16 m_{r e f}$ and $m$ vs. time during overloading for SFDQ

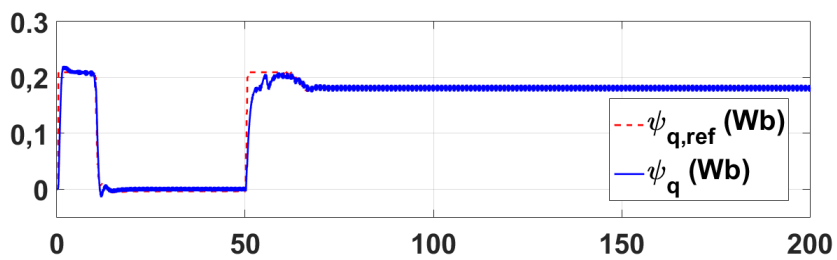

Fig. $17 \psi_{q, r e f}$ and $\psi_{q}$ vs. time during overloading for SFDQ

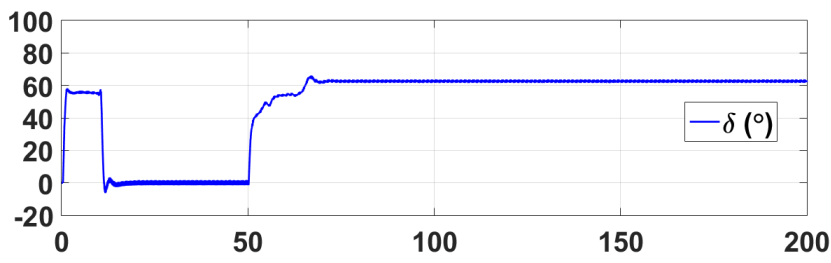

Fig. $18 \delta$ (in degrees) vs. time during overloading for SFDQ

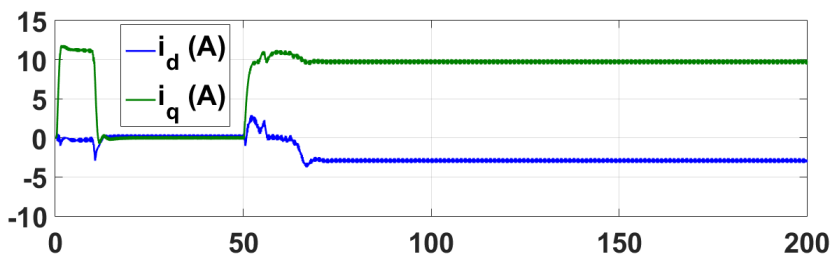

Fig. $19 i_{d}$ and $i_{q}$ vs. time during overloading for SFDQ

of the figure when both $\psi_{x, \text { ref }}$ and $\psi_{x}$ are distorted. In the case of Fig. 17 the tracking is error-free due to the fact that PI-type controllers are being used in the flux vector controller of SFDQ. Also, the shape of $\psi_{q, \text { ref }}$ and $\psi_{q}$ are the same as $m_{r e f}$ and $m$, respectively. This can be explained by the linear relationship between $\psi_{q}$ and $m$ (see Eq. (4) in Part 1). The activation point of the the $\psi_{\text {ref }}$-controller can be noticed on Fig. 17 as well due to the aforementioned linear relationship.

Fig. 13 and Fig 18 show $\delta$ vs. time for both methods. It can be noticed that $\delta$ is well under $90^{\circ}$ in both cases. This can be explained by the fact that $\psi_{d, r e f}$ and $\psi_{\text {q,ref }}$ are synthesized 
directly by the reference controller and because the two components form a right triangle (see Fig. 1 in Part 1) the reference load-angle is unable to reach $90^{\circ}$ (implicit limitation). Fig. 14 and Fig. 19 show the d-and the q-components of the stator current vector for both methods. It can be noticed on both figures that the shape of $i_{q}$ is the same as that of $m$ in both cases due to the linear relationship between $i_{q}$ and $m$.

Finally, in order to demonstrate the stability of SFXY and SFDQ during overload-conditions, Figs. 20-23 show the simulation results for a process which consists of a speed-reference step of $3000 \mathrm{rpm}$ at $0 \mathrm{~ms}$ and a loadtorque step of $7.6 \mathrm{Nm}$ at $50 \mathrm{~ms}$. Although the $7.6 \mathrm{Nm}$ is approx. $10 \%$ higher than the maximum load-torque step that can be compensated on $3000 \mathrm{rpm}$ in the case of both methods (see Table 3), SFXY and SFDQ do not collapse, they try to compensate for the load-torque.

\section{A comparison of overload-capabilities}

Table 3 shows the overload-capabilities of IMDTC-SVM SFXY and SFDQ. The indicated values are the maximum load-torque steps that can be compensated on the specific speed with each method (these are expressed relative to the nominal torque of the motor in the brackets). Due to the fact that the simulation environment, the simulation parameters, etc. were the same as in [30] and Part 1 the results are comparable with those of the other DTC-SVM methods. The values indicated in Table 3 are given for one decimal place only (without rounding up) due to the very high overload-capability.

According to Table 3 of this article and Table 2 and 3 of Part 1 the overload-capabilities of SFXY and SFDQ are superior to that of either the classical DTC-SVM or the MDTC-SVM on every speed. The improvement in the case of IMDTC-SVM SFXY is $25 \%$ compared to MDTCSVM and $83 \%$ compared to classical DTC-SVM, while in the case of IMDTC-SVM SFDQ these are $27 \%$ and $85 \%$, respectively. These advancements can be contributed to the following features of the simplified forms of IMDTC-SVM:

- The forming of the stator flux amplitude reference signal $\left(\psi_{r e f}\right)$ is dependent on the electromagnetic torque reference $\left(m_{\text {ref }}\right)$, whereas in the case of classical DTC-SVM and MDTC-SVM the two are independent of each other [30].

- There is a stator flux amplitude reference controller which increases the stator flux amplitude reference signal if necessary.

- The voltage vector calculator is adaptive instead of a standard one.

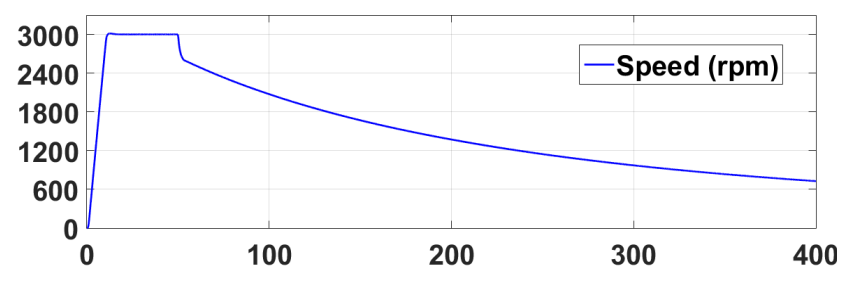

Fig. 20 Speed vs. time for a $7.6 \mathrm{Nm}$ load-torque step at $50 \mathrm{~ms}$ on $3000 \mathrm{rpm}$ in the case of SFXY

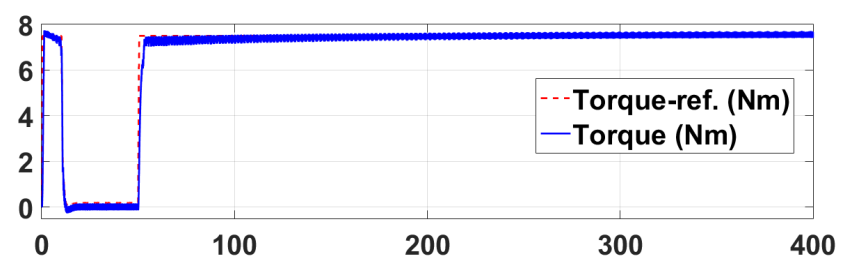

Fig. $21 m_{r e f}$ and $m$ vs. time for a $7.6 \mathrm{Nm}$ load-torque step at $50 \mathrm{~ms}$ on $3000 \mathrm{rpm}$ in the case of SFXY

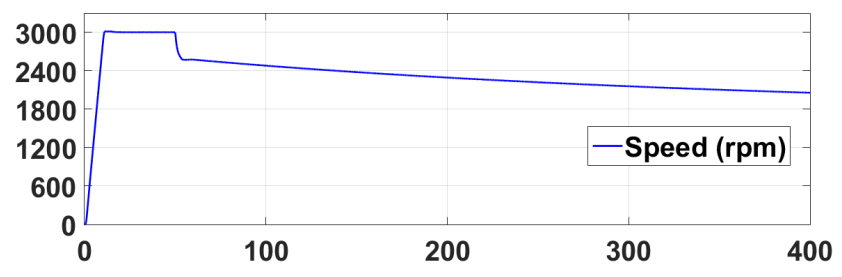

Fig. 22 Speed vs. time for a $7.6 \mathrm{Nm}$ load-torque step at $50 \mathrm{~ms}$ on $3000 \mathrm{rpm}$ in the case of SFDQ

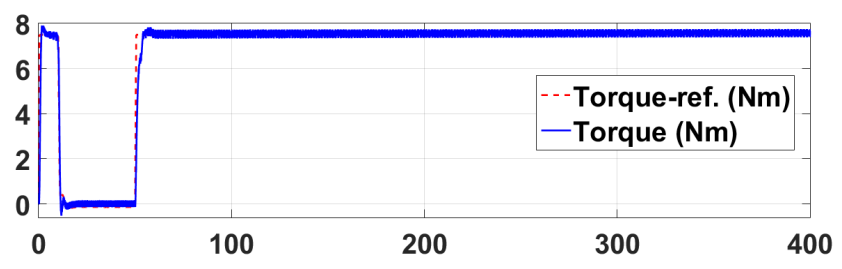

Fig. $23 m_{r e f}$ and $m$ vs. time for a $7.6 \mathrm{Nm}$ load-torque step at $50 \mathrm{~ms}$ on $3000 \mathrm{rpm}$ in the case of SFDQ

Table 3 Overload-capabilities of IMDTC-SVM SFXY and SFDQ

\begin{tabular}{ccc}
\hline & IMDTC-SVM SFXY & IMDTC-SVM SFDQ \\
\hline $0 \mathrm{rpm}$ & $7.4 \mathrm{Nm}(569 \%)$ & $7.4 \mathrm{Nm}(569 \%)$ \\
$1000 \mathrm{rpm}$ & $7.4 \mathrm{Nm}(569 \%)$ & $7.4 \mathrm{Nm}(569 \%)$ \\
$2000 \mathrm{rpm}$ & $7.3 \mathrm{Nm}(562 \%)$ & $7.4 \mathrm{Nm}(569 \%)$ \\
$3000 \mathrm{rpm}$ & $6.9 \mathrm{Nm}(531 \%)$ & $7 \mathrm{Nm}(538 \%)$ \\
\hline
\end{tabular}

According to Table 3 the difference between the overload-capabilities of SFXY and SFDQ is small. This difference can be explained by the fact that in the case of SFDQ PI-type controllers are being used in the flux vector controller, while in the case of SFXY only P-type controllers are being used in the flux vector controller. 
However, the overload-capabilities of the simplified forms are slightly smaller than that of the standard IMDTC-SVM. This can be explained by the fact that the stator flux vector itself is dependent on the poleflux-vector $\left(\bar{\psi}=\overline{\psi_{p}}+L_{d} \bar{i}\right)$, $\psi_{d}$ and $\psi_{q}$ are both dependent on the stator current vector (this is true for $\psi_{x}$ and $\psi_{y}$ as well) which means that there is a coupling between the two components and thus in this case it is the best / most decoupled solution if the amplitude of the stator flux vector and the load-angle are controlled by separate controllers. The aforementioned small disadvantage comes along with the advantages that the simplified forms are remarkably simpler in structure, they require significantly less computation and the tuning of the complete control system in the case of SFXY is much simpler.

\section{Conclusions}

In this article simplified forms of Improved Modified DTC-SVM (IMDTC-SVM) introduced in Part 1 have been invented. It has been demonstrated that the simplified

\section{References}

[1] Szalay, I., Kohlrusz, G., Fodor, D. "Modeling of slotless surface-mounted PM synchronous motor for sensorless applications", In: 2014 IEEE International Electric Vehicle Conference (IEVC), Florence, Italy, 2014, pp. 1-5. https://doi.org/10.1109/IEVC.2014.7056198

[2] Döbler, R., Schuhmann, T., Inderka, R. B., Malottki, S. V. "High performance drive for electric vehicles - System comparison between three and six phase permanent magnet synchronous machines", In: 2016 18th European Conference on Power Electronics and Applications (EPE'16 ECCE Europe), Karlsruhe, Germany, 2016, pp. 1-10.

https://doi.org/10.1109/EPE.2016.7695475

[3] Járdán, R. K., Stumpf, P., Varga, Z., Endisch, C., Sipos, P., Simon, M. "Laboratory system for measurement of iron losses in high speed drives", International Journal of Hydrogen Energy, 41(29), pp. 12650-12658, 2016.

https://doi.org/10.1016/j.ijhydene.2016.01.061

[4] Jardan, R. K., Varga, Z., Stumpf, P., Nagy, I., Endisch, C., Sipos, P., Simon, M. "Development of a dedicated laboratory system for measurement of iron losses in high speed PMSM", In: 2015 IEEE International Conference on Industrial Technology (ICIT), Seville, Spain, 2015, pp. 708-713. https://doi.org/10.1109/ICIT.2015.7125181

[5] Fodor, D., Medve, H., Szalay, I., Kulcsár, T. "Sensorless Rotor Position Detection of PMSM for Automotive Application", Hungarian Journal of Industry and Chemistry, 38(2), pp. 207-210, 2010.

[6] Számel, L., Vajsz, T. "The Special Characteristics of Stepping Motor Drives and a New Type of Classification", Acta Polytechnica Hungarica, 13(7), pp. 83-102, 2016. https://doi.org/10.12700/APH.13.7.2016.7.5 forms have a very high overload-capability, surpassing even that of the MDTC-SVM introduced in [30] and the classical DTC-SVM. The increase is significant in both cases, approximately $25 \%$ for both methods compared to MDTC-SVM and approximately $85 \%$ for both methods compared to classical DTC-SVM. Also, the simplified forms are stable during overload-conditions as well.

In addition, it has been concluded that there is no significant difference between all forms of IMDTC-SVM, classical DTC-SVM and MDTC-SVM from the point of view of the torque-ripple generated and the torque-control dynamic performance.

The simplified forms can be effectively used in applications where a slightly lower overload-capability than that of the standard IMDTC-SVM is acceptable but lower computation requirements and a simpler control structure are advantageous. Also, in applications where a simple tuning procedure of the complete control system is advantageous, the utilization of IMDTC-SVM SFXY is recommended.

[7] Buja, G. S., Kazmierkowski, M. P. "Direct torque control of PWM inverter-fed AC motors - a survey", IEEE Transactions on Industrial Electronics, 51(4), pp. 744-757, 2004. https://doi.org/10.1109/TIE.2004.831717

[8] Juhasz, G., Halasz, S., Veszpremi, K. "New aspects of a direct torque controlled induction motor drive", In: Proceedings of IEEE International Conference on Industrial Technology 2000, Goa, India, 2000, pp. 43-48. https://doi.org/10.1109/ICIT.2000.854094

[9] Juhász, G., Halász, S., Veszprémi, K. "Simulation and Measurement of Direct Torque Controlled IM Drive", In: Proceedings of 9th International Conference on Power Electronics and Motion Control, EPE-PEMC 2000, Kosice, Slovakia, 2000, pp. 124-129.

[10] Szabó, G., Veszprémi, K., Schmidt, I. "MATLAB and Simulinkbased controlled electric drive software development", In: 2017 International Young Engineers Forum (YEF-ECE), Almada, Portugal, 2017, pp. 79-84. https://doi.org/10.1109/YEF-ECE.2017.7935645

[11] Schmidt, I., Veszprémi, K. "Drive Control", Budapest University of Technology and Economics Department of Electric Power Engineering, Budapest, Hungary, 2012.

[12] Suto, Z., Nagy, I. "Numerous subharmonic states in Direct Torque Controlled Induction Machine", In: 2009. SSD '09. 6th International Multi-Conference on Systems, Signals and Devices, Djerba, Tunisia, 2009, pp. 1-7. https://doi.org/10.1109/SSD.2009.4956792

[13] Suto, Z., Nagy, I., Masada, E. "Nonlinear dynamics in direct torque controlled induction machines analyzed by recurrence plots", In: 2007 European Conference on Power Electronics and Applications, Aalborg, Denmark, 2007, pp. 1-10. https://doi.org/10.1109/EPE.2007.4417522 
[14] Veszprémi, K. "Optimizing the Dynamic Behavior of Direct Controls of Voltage-source Converters", Electric Power Components and Systems, 37(9), pp. 1014-1035, 2009. https://doi.org/10.1080/15325000902918883

[15] Schmidt, L., Veszpremi, K. "Application of direct controls to variable-speed wind generators", In: 2005. ICIECA 2005. International Conference on Industrial Electronics and Control Applications, Quito, Ecuador, 2005, pp. 6. https://doi.org/10.1109/ICIECA.2005.1644340

[16] Veszpremi, K., Schmidt, I. "Direct controls in voltage-source converters - generalizations and deep study", In: 2008 EPE-PEMC 2008. 13th Power Electronics and Motion Control Conference, Poznan, Poland, 2008, pp. 1803-1810.

https://doi.org/10.1109/EPEPEMC.2008.4635527

[17] Malinowski, M., Jasinski, M., Kazmierkowski, M. P. "Simple direct power control of three-phase PWM rectifier using space-vector modulation (DPC-SVM)", IEEE Transactions on Industrial Electronics, 51(2), pp. 447-454, 2004. https://doi.org/10.1109/TIE.2004.825278

[18] Malinowski, M., Kazmierkowski, M. P., Hansen, S., Blaabjerg, F., Marques, G. D. "Virtual-flux-based direct power control of three-phase PWM rectifiers", IEEE Transactions on Industry Applications, 37(4), pp. 1019-1027, 2001. https://doi.org/10.1109/28.936392

[19] Swierczynski, D., Kazmierkowski, M. P., Blaabjerg, F. "DSP Based Direct Torque Control of Permanent Magnet Synchronous Motor (PMSM) Using Space Vector Modulation (DTC-SVM)", In: Proceedings of the 2002 IEEE International Symposium on Industrial Electronics, 2002. ISIE, L'Aquila, Italy, 2002, pp. $723-727$.

https://doi.org/10.1109/ISIE.2002.1025821

[20] Swierczynski, D., Kazmierkowski, M. P. "Direct torque control of permanent magnet synchronous motor (PMSM) using space vector modulation (DTC-SVM)-simulation and experimental results", In: IEEE 2002 28th Annual Conference of the Industrial Electronics Society, IECON 02, Sevilla, Spain, 2002, pp. 751-755. https://doi.org/10.1109/IECON.2002.1187601

[21] Niu, F., Wang, B., Babel, A. S., Li, K., Strangas, E. G. "Comparative Evaluation of Direct Torque Control Strategies for Permanent Magnet Synchronous Machines", IEEE Transactions on Power Electronics, 31(2), pp. 1408-1424, 2016. https://doi.org/10.1109/TPEL.2015.2421321

[22] Abosh, A. H., Zhu, Z. Q., Ren, Y. "Reduction of Torque and Flux Ripples in Space Vector Modulation-Based Direct Torque Control of Asymmetric Permanent Magnet Synchronous Machine", IEEE Transactions on Power Electronics, 32(4), pp. 2976-2986, 2017. https://doi.org/10.1109/TPEL.2016.2581026

[23] Vafaie, M. H., Dehkordi, B. M., Moallem, P., Kiyoumarsi, A. "Improving the Steady-State and Transient-State Performances of PMSM Through an Advanced Deadbeat Direct Torque and Flux Control System", IEEE Transactions on Power Electronics, 32(4), pp. 2964-2975, 2017

https://doi.org/10.1109/TPEL.2016.2577591
[24] Wang, X., Wang, Z., Cheng, M., Hu, Y. "Remedial Strategies of T-NPC Three-Level Asymmetric Six-Phase PMSM Drives Based on SVM-DTC", IEEE Transactions on Industrial Electronics, 64(9), pp. 6841-6853, 2017. https://doi.org/10.1109/TIE.2017.2682796

[25] Vafaie, M. H., Dehkordi, B. M., Moallem, P., Kiyoumarsi, A. "A New Predictive Direct Torque Control Method for Improving Both Steady-State and Transient-State Operations of the PMSM", IEEE Transactions on Power Electronics, 31(5), pp. 3738-3753, 2016. https://doi.org/10.1109/TPEL.2015.2462116

[26] Zhang, Z., Zhao, Y., Qiao, W., Qu, L. "A Space-Vector-Modulated Sensorless Direct-Torque Control for Direct-Drive PMSG Wind Turbines", IEEE Transactions on Industry Applications, 50(4), pp. 2331-2341, 2014. https://doi.org/10.1109/TIA.2013.2296618

[27] Wang, Z., Wang, X., Cao, J., Cheng, M., Hu, Y. "Direct Torque Control of T-NPC Inverters-Fed Double-Stator-Winding PMSM Drives With SVM", IEEE Transactions on Power Electronics, 33(2), pp. 1541-1553, 2018. https://doi.org/10.1109/TPEL.2017.2689008

[28] Choi, Y.-S., Choi, H. H., Jung, J.-W. "Feedback Linearization Direct Torque Control With Reduced Torque and Flux Ripples for IPMSM Drives", IEEE Transactions on Power Electronics, 31(5), pp. 3728-3737, 2016.

https://doi.org/10.1109/TPEL.2015.2460249

[29] Fan, Y., Zhang, L., Cheng, M., Chau, K. T. "Sensorless SVPWMFADTC of a New Flux-Modulated Permanent-Magnet Wheel Motor Based on a Wide-Speed Sliding Mode Observer", IEEE Transactions on Industrial Electronics, 62(5), pp. 3143-3151, 2015. https://doi.org/10.1109/TIE.2014.2376879

[30] Vajsz, T., Számel, L., Rácz, G. "A Novel Modified DTC-SVM Method with Better Overload-capability for Permanent Magnet Synchronous Motor Servo Drives", Periodica Polytechnica Electrical Engineering and Computer Science, 61(3), pp. 253-263, 2017.

https://doi.org/10.3311/PPee.10428

[31] Futo, A., Varjasi, I., Suto, Z. "Current ripple calculation for dead time compensation in three phase PWM inverters", In: 2014 IEEE International Energy Conference (ENERGYCON), Cavtat, Croatia, 2014, pp. 195-201. https://doi.org/10.1109/ENERGYCON.2014.6850428

[32] Mahlfeld, H., Schuhmann, T., Döbler, R., Cebulski, B. "Impact of overmodulation methods on inverter and machine losses in voltage-fed induction motor drives", In: 2016 XXII International Conference on Electrical Machines (ICEM), Lausanne, Switzerland, 2016, pp. 1064-1070. https://doi.org/10.1109/ICELMACH.2016.7732657 